\title{
O CRONOTOPO EM SÃO BERNARDO
}

Josalba Fabiana dos Santos*

A

s relações espaço-temporais dentro da ficção têm movimentado um crescente interesse nos estudiosos da literatura e não é à toa, pois as discussões referentes especialmente ao tempo apontam sobretudo para uma velha polêmica: aproximações e distanciamentos entre ficção e realidade. Se aceitamos a idéia de que somos feitos do que vivemos e que o que vivemos forma uma história, também aceitamos que essa história se dá dentro de um passado e que isso tudo é tempo ou se passa dentro do tempo e, logicamente, dentro do espaço, isto é, num momento e em algum lugar, sempre. Esses princípios, que de certa maneira estabelecem a realidade, também estabelecem a literatura e podem nortear um texto de mais ou menos verossimilhança, assim como outros elementos constitutivos naturalmente. Mas o tempo e o espaço juntos dão unidade à obra literária, estabelecem pontos de encontro e desencontro. É improvável que se crie uma ou mais personagens que não estejam em algum lugar e em determinado momento, como é improvável ou até mesmo impossível, que por mais que essa personagem se mantenha no mesmo lugar o tempo não se escoe, ou seja, que não haja um começo e um fim, que deverão ser estabelecidos no mínimo pela própria enunciação, iniciada numa determinada página e finalizada em algum momento do livro no seu sentido material inclusive.

* Mestranda da Universidade Federal do Paraná 
O estudo que aqui apresentar-se-á da aplicação do conceito de cronotopo de Bakhtin ${ }^{1}$ em São Bernardo, ${ }^{2}$ de Graciliano Ramos, não me parece de forma nenhuma passível de ser restrito a essa obra ou a qualquer outra, pois trata-se de terminologia utilizada em larga escala, que implica na possibilidade de um bom leque de leituras.

Bakhtin desenvolve seu estudo sobre a teoria do cronotopo fazendo uma espécie de levantamento histórico-literário em que se observam os diferentes tratamentos que tiveram a questão do tempo e do espaço desde o romance grego até o final da Idade Média. Trata-se de um trabalho de fôlego e não pretendo resenhá-lo e sim buscar nele alguns dos elementos que me parecem traduzir os principais pressupostos que norteiam a teoria do cronotopo para Bakhtin.

Em primeiro lugar, Bakhtin não dissocia tempo de espaço, daí o nome de cronotopo (tempo-espaço) para a teoria. Mas, dos dois elementos, é ao tempo que ele dá maior ênfase. Como acontece com outros estudiosos, como Paul Ricoeur, por exemplo, Bakhtin também vê o tempo como uma espécie de grande ponte entre a ficção e a realidade, ou seja, as relações temporais dentro do romance estabelecem um elo com a realidade, um ponto de ligação.

A obra e o mundo nela representado penetram no mundo real enriquecendo-o, e o mundo real penetra na obra e no mundo representado, tanto no processo da sua criação como no processo subseqüente da vida, numa constante renovação da obra e numa percepção criativa dos ouvintes-leitores. Esse processo de troca é sem dúvida cronotópico por si só: ele se realiza principalmente num mundo social que se desenvolve historicamente, mas também sem se separar do espaço histórico em mutação. Pode-se mesmo falar de um cronotopo criativo particular, no qual ocorre essa troca da obra com a vida e se realiza a vida particular de uma obra. (BAKHTIN, 1988, p. 358-359)

Mas não é só isso. Vou passar a uma questão que será muito valiosa na leitura de São Bernardo, a da imagem. Para o pensador russo, a imagem é estabelecida a partir do tempo. Sem dúvida essa relação entre imagem e tempo é fundamental, pois a mudança na imagem ou a constituição da imagem por si

1 BAKHTIN, Mikhail. Formas de tempo e de cronotopo no romance. In: Questões de literatura e de estética. Trad. de Aurora Fornoni Bemardini et al. São Paulo: Hucitec, 1988.

2 RAMOS, Graciliano. Säo Bernardo. Rio de Janeiro: Record, 1988. 
só estabelece uma passagem no tempo. E a imagem pode ser a de uma personagem, mas também pode ser a de um lugar, a de um espaço.

Bakhtin aponta vários cronotopos, como o do encontro, o da estrada e outros. Mas esses dois me interessam especialmente e serão retomados adiante. $\mathrm{Na}$ verdade, saliento na teoria bakhtiniana os pontos que me parecem importantes para a leitura de São Bernardo e obviamente no que ela tem de estrutural, isto é, no que ela tem de básico, de conceitual.

Há também uma série de discussōes e exemplos no que se refere à dimensão do espaço público e do privado. São Bernardo, a fazenda, é sobretudo o espaço privado, mas nem por ser um espaço privado se condiciona a um único discurso, pois reúne várias tendências ideológicas, pontos de vista não só diferentes mas até divergentes, opostos, mas isso tudo dentro de um determinado tempo. São Bernardo não é sempre a mesma fazenda, lá muita coisa muda. Mas é espaço privilegiado e pretendo levantar aqui os momentos em que essa grandiosa fazenda decai, ascende e, finalmente, decai definitivamente. Ou seja, há dois momentos de glória e dois de derrocada, mas não há equivalência nem na glória e nem na derrocada.

O contexto histórico também é relevante para Bakhtin e na obra aqui estudada é notória sua importância: a atuação da história, do público, sobre o privado.

Finalmente falarei da relação entre o tempo da enunciação, que Bakhtin chama de narração, e o tempo do enunciado, que é o tempo daquilo que é contado, que é narrado.

\section{A obra e a teoria}

São Bernardo narra a história de um empreendedor e de sua fazenda, que dá título à obra, o lugar "mais importante do mundo" para ele; seu envolvimento com Madalena e todo o processo que culmina no fim abrupto e implacável de Paulo Honório e de sua propriedade.

O primeiro ponto que abordarei será o da imagem, sempre associada à condição cronotópica, que é, segundo Bakhtin a condição por excelência da imagem:

Pode-se dizer francamente que o gênero e as variedades de gênero são determinadas justamente pelo cronotopo, sendo que em literatura o princípio condutor do cronotopo é o tempo. $\mathrm{O}$ 
cronotopo como categoria conteudístico-formal determina (em medida significativa) também a imagem do indivíduo na literatura; essa imagem sempre é fundamentalmente cronotópica. (BAKHTIN, 1988, p. 212)

Isto é, a imagem que a personagem faz de si ou das outras personagens está condicionada a uma dada situação que se dá num dado lugar e num dado tempo. Como São Bernardo é narrado em primeira pessoa e o tempo da enunciação obviamente não coincide com o tempo do enunciado, há uma definição temporal: o narrador Paulo Honório está num tempo futuro em relação ao personagem Paulo Honório. Como afirma Bakhtin: "Se eu narrar (escrever) um fato que acaba de acontecer comigo, já me encontro, como narrador (ou escritor), fora do tempo-espaço onde o evento se realizou." (BAKHTIN, 1988, p. 360). E, pelo que é possível de se deduzir no decorrer do texto, o espaço ocupado pelo narrador é o de São Bernardo, a fazenda, enquanto o espaço ocupado pelo personagem Paulo Honório é variável, visto que sua história é narrada desde a mais tenra idade.

Mas qual a imagem que o narrador constrói de si logo no início da narrativa:

Começo declarando que me chamo Paulo Honório, peso oitenta e nove quilos e completei cinqüenta anos pelo São Pedro. A idade, o peso, as sobrancelhas cerradas e grisalhas, este rosto vermelho e cabeludo têm-me rendido muita consideração. Quando me faltavam estas qualidades, a consideração era menor. (RAMOS, 1988, p. 12)

Paulo Honório associa sua aparência física, sua idade, enfim, atributos adquiridos pelo tempo, com respeito. Para o narrador a sua relevância social aumentou a partir da passagem do tempo. $O$ que chama a atenção nessa citação é que aqui ainda estamos diante de um homem poderoso e rico, e mesmo que se pense que poder e riqueza também necessitam de tempo para serem acumulados e renderem respeito, é justamente com motivos mais facilmente relacionados com o tempo, como a aparência física e a idade, que Paulo Honório se identifica para criar a própria imagem. Na verdade, o narrador, extremamente conciso, resolve em poucas linhas o lugar social que ocupa, o de ser respeitado, e também dá uma descrição física de si mesmo. 
Porém, se os traços físicos do narrador, homem maduro de cinqüenta anos, não se alteram sensivelmente no decorrer do romance, por outro lado a forma como são apresentados muda bastante:

Confio em mim. Mas exagerei os olhos bonitos do Nogueira, a roupa bem feita, a voz insinuante. Pensei nos meus oitenta e nove quilos, neste rosto vermelho de sobrancelhas espessas. Cruzei descontente as mãos enormes, cabeludas, endurecidas em muitos anos de lavoura. Misturei tudo ao materialismo e ao comunismo de Madalena - e comecei a sentir ciúmes. (RAMOS, 1988, p. 132)

Diante do possível rival, Paulo Honório vê com amargura a si próprio, a imagem que num dado momento lhe rendia prestígio social em outro lhe coloca $\mathrm{cm}$ condição de desvantagem. Não tem os olhos do Nogueira, o bom gosto no vestir e nem tão pouco a sonoridade da voz. Em contrapartida, Nogueira não tem o seu peso e nem seus traços grosseiros. Essa é uma situação do passado, da personagem Paulo Honório e quanto mais o narrador mergulha nesse passado mais essa imagem negativa vai se acentuando:

Com o dr. Magalhães, homem idoso! Considerei que também eu cra um homem idoso, esfreguei a barba, triste. Em parte, a culpa era minha: não me tratava. Ocupado com o diabo da lavoura, ficava três, quatro dias sem raspar a cara. E quando voltava do serviço, trazia lama até nos olhos: dêem por visto um porco. Metia-me em água quente, mas não havia esfregação que tirasse aquilo tudo. (RAMOS, 1988, p. 138)

Ainda enleado no ciúme, Paulo Honório vê rivais por todos os lados e à medida que essa visão aumenta a sua imagem piora, o turbilhão cresce e ele se sente cada vez mais impossibilitado na sua condição de homem de obter a consideração da esposa, Madalena: "Que mãos enormes! As palmas eram enormes, gretadas, calosas, duras como casco de cavalo. E os dedos eram também enormes, curtos e grossos. Acariciar uma fêmea com semelhantes mãos!" (RAMOS, 1988, p. 138)

No avançar do texto é possível de se perceber que os contornos de Paulo Honório vão se tornando cada vez mais marcados, mais acentuados, até tomarem ares de disformidade, de monstruosidade, o que se aproxima com seu estado 
emocional: "Foi este modo de vida que me inutilizou. Sou um aleijado. Devo ter um coração miúdo, lacunas no cérebro, nervos diferentes dos nervos dos outros homens. E um nariz enorme, uma boca enorme, dedos enormes." (RAMOS, 1988, p. 187)

Essa citação está bem próxima das últimas linhas do romance, quando narrador e personagem se fundem e o tempo da enunciação e o tempo do enunciado também. Por tanto, torna-se possível dizer que Paulo Honório ao buscar o passado aniquila irremediavelmente seu futuro, pois seu processo é o da destruição da própria imagem, enquanto inicialmente digna de respeito e consideração, para o surgimento cada vez mais evidente de um ser monstruoso.

Passo ao cronotopo do encontro, que em São Bernardo também se realiza no sentido do desencontro, pois o encontro de Paulo Honório e Madalena é frustrado por uma série de desencontros que se dão no sentido ideológico, emocional, e, é claro, no tempo e no espaço. Diz Bakhtin:

Em qualquer encontro (como já mostramos na análise do romance grego) a definição temporal ("num mesmo tempo") é inseparável da definição espacial ("num mesmo lugar"). E no motivo negativo - "não se encontraram", "se separaram" - a cronotopicidade é mantida, mas um ou outro membro do cronotopo é dado com um signo negativo: não se encontraram porque não estavam em dado lugar ao mesmo tempo, ou ao mesmo tempo encontravam-se em lugares diferentes. (BAKHTIN, 1988, p. 222)

O primeiro encontro de Paulo Honório com Madalena é metonímico, os amigos falavam de "umas pernas e de uns peitos", que ele só vem a conhecer dias depois num encontro social em casa do dr. Magalhães:

Encontrei-o [Magalhães] à noitinha no salão, que servia de gabinete de trabalho, com a filha e três visitantes: João Nogueira, uma senhora de preto, alta, velha, magra, outra senhora moça, loura e bonita.

Estavam calados, em dois grupos, os homens separados das mulheres. (RAMOS, 1988, p. 64)

Madalena é a moça "loura e bonita". O encontro se dá em lugar que se não é público, denota uma situação social, o que é bastante freqüente, segundo 
Bakhtin: "O cronotopo real do encontro tem constantemente lugar nas organizações da vida social e nacional. Todos conhecem os vários tipos de encontros sociais organizados e o significado deles." (BAKHTIN, 1988, p. 223)

O próximo encontro entre eles se dará em local declaradamente público, a estação ferroviária. Paulo Honório se constrange ao ver Madalena, não consegue ser natural: "Na estação d. Glória apresentou-me a sobrinha, que tinha ido recebê-la. Atrapalhei-me e, para desocupar a mão, deixei cair um dos pacotes que ia entregar ao ganhador." (RAMOS, 1988, p. 81)

Daí para frente, pouco a pouco, o narrador ganha o espaço da privacidade da casa de Madalena e de sua tia, d. Glória. Somada a essa aproximação física está uma aproximação afetiva. O casamento é armado rapidamente e as duas mulheres se mudam para São Bernardo. Após discussão com Madalena, Paulo Honório afirma: "Joguei o guardanapo sobre os pratos, antes da sobremesa, e levantei-me. Um bate-boca oito dias depois do casamento! Mau sinal. Mas atirei a responsabilidade para d. Glória, que só tinha dito uma palavra." (RAMOS, 1988, p. 100-101). Paulo Honório associa a discussão com o pouco tempo do casamento, oito dias, é o início do desencontro. Desencontro que se perpetua com o suicídio de Madalena, com a então infinita não coincidência espaçotemporal entre ela e Paulo Honório.

Bakhtin dedica especial atenção em sua análise do romance de aventuras e de costumes ao cronotopo da estrada e afirma:

A concretude do cronotopo da estrada permite que se desenvolva amplamente nele a vida corrente. Entretanto, essa vida corrente desenrola-se, por assim dizer, à parte da estrada, nos seus caminhos laterais. O personagem principal e os principais acontecimentos que decidem sua vida estão fora da vida cotidiana. Ele apenas a observa, às vezes imiscui-se como uma força heterogênea, outras, ele mesmo veste a máscara da vida cotidiana, mas não participa verdadeiramente da vida diária e nem é determinado por ela. (BAKHTIN, 1988, p. 242)

Em São Bernardo a estrada ajuda a marcar o tempo que passa e a própria ascendência e decadência da fazenda. $O$ tempo da enunciação inicia-se com uma estrada de rodagem que está sendo reparada, o que pode ter duplo sentido, tanto o de que havia um processo de decadência se iniciando e que isso portanto implicava na necessidade do conserto, como o de que tal processo ainda não teria se iniciado e que a estrada era periodicamente conservada, marcando assim 
uma certa opulência. Ao final da enunciação esse quadro já mudou bastante, passaram-se quatro meses e a derrocada é evidente:

Sol, chuva, noites de insônia, cálculos, combinações, violências, perigos - e nem sequer me resta a ilusão de ter realizado obra proveitosa. O jardim, a horta, o pomar - abandonados; os marrecos de Pequim - mortos; o algodão, a mamona - secando. E as cercas dos vizinhos, inimigos ferozes, avançam.

Está visto que, cessando esta crise, a propriedade se poderia reconstituir e voltar a ser o que era. A gente do eito se esfalfaria de sol a sol, alimentada com farinha de mandioca e barbatanas de bacalhau; caminhões rodariam novamente, conduzindo mercadorias para a estrada de ferro; a fazenda se encheria outra vez de movimento e rumor. (RAMOS, 1988, p. 181)

O tempo do enunciado apresenta a estrada de outras maneiras. Paulo Honório ainda está tentando adquirir São Bernardo de Padilha filho e nesse momento a propriedade está arruinada, havia acabado seu periodo áureo com Padilha pai:

A última letra se venceu num dia de inverno. Chovia que era um deus-nos-acuda. De manhã cedinho mandei Casimiro Lopes selar o cavalo, vesti o capote e parti. Duas léguas em quatro horas. O caminho era um atoleiro sem fim. Avistei as chaminés do engenho do Mendonça e a faixa de terra que sempre foi motivo de questão entre ele e Salustiano Padilha. Agora as cercas de Bom-Sucesso iam comendo S. Bernardo. (RAMOS, 1988, p. 20)

O que depois vai se tornar uma estrada de rodagem é nesse momento um atoleiro sem fim e combina perfeitamente com a situação em que Luís Padilha vinha mantendo a fazenda.

Além de todos esses aspectos em que a estrada aparece relacionada com o tempo e sempre marcando ou a opulência ou a decadência de São Bernardo, ainda há outro, o da relação com a vida, ou nesse caso com a narrativa de Paulo Honório: 
Continuemos. Tenciono contar a minha história. Difícil. Talvez deixe de mencionar particularidades úteis, que me pareçam acessórias e dispensáveis. Também pode ser que, habituado a tratar com matutos, não confie suficientemente na compreensão dos leitores e repita passagens insignificantes. De resto isto vai arranjado sem nenhuma ordem, como se vê. Não importa. Na opinião dos caboclos que me servem, todo o caminho dá na venda. (RAMOS, 1988, p. 10)

Paulo Honório associa a narrativa com um caminho, com uma estrada. Mas onde dá São Bernardo? Já adiantei que, apesar de haver um certo sabor de vencedor no narrador desse início de romance, esse tom muda radicalmente, $\mathrm{e}$ a decadência da fazenda, da estrada, se coadunam perfeitamente com a decadência do próprio Paulo Honório. Parece que ao final da narrativa ele chega a um lugar que não era exatamente o esperado, o desejado.

São Bernardo é a fazenda onde vive Paulo Honório e não é propriedade adquirida por herança, é resultado da faceta mais empreendedora da personagem, algo que se fez a partir da sua determinação e truculência, algo construído por ele. $\mathrm{O}$ mundo fora da fazenda pouco aparece, é o privado em detrimento do público. Afirma Paulo Honório para Madalena: “ - [...] O cinema, o bar, os convites, a loteria, o bilhar, o diabo, não temos nada disso, e às vezes nem sabemos em que gastar dinheiro." (RAMOS, 1988, p. 105). Na verdade, nenhum desses locais aparece em São Bernardo em qualquer momento. As poucas referências ao espaço público se referem à viagem de Paulo Honório a Maceió para uma desforra do Costa Brito, que o teria caluniado no jornal.

Mas o espaço público, o contexto histórico, invadem São Bernardo à revelia de seu proprietário:

Padre Silvestre recebeu-me friamente. Depois da revolução de outubro, tornou-se uma fera, exige devassas rigorosas e castigos para os que não usaram lenços vermelhos. Torceu-me a cara. $E$ éramos amigos. Patriota. Está direito: cada qual tem as suas manias. (RAMOS, 1988, p. 7)

A citação se refere à Revolução de 30 e é mencionada logo nas primeiras páginas do romance. No decorrer do texto é possível se perceber que a fazenda sofrerá muito com os efeitos econômicos desse fato externo, aliados à apatia crescente de Paulo Honório, que ao final vê a propriedade e o mundo todo como 
espaços impossíveis de se viver: "O mundo que me cercava ia-se tornando um horrivel estrupício. E o outro, grande, era uma balbúrdia, uma confusão dos demônios, estrupício muito maior." (RAMOS, 1988, p. 174)

Paulo Honório não consegue se adaptar aos novos tempos impostos por esse mundo grande, pelo mundo público. Parece que o narrador não consegue se mexer e de fato ao final da narrativa ele menciona uma imobilidade física e ao que tudo indica essa imobilidade está diretamente atrelada a sua incapacidade de autotransformação.

Mas, no apogeu de São Bernardo nas mãos de Paulo Honório, a fazenda se torna um reduto que reúne variadas tendências: do seu proprietário capitalista a comunistas como Padilha, o ex-proprietário. Há também figuras de extremadireita como o advogado Nogueira, ou mesmo humanistas como padre Silvestre e Madalena que oscilam ora dentro e ora fora da tendência comunista.

O desencontro ideológico de Paulo Honório e Madalena se dá precisamente em função da administração de São Bernardo. A esposa não admite os abusos cometidos pelo marido e este não admite as intervenções da esposa. Além disso, Paulo Honório é pouco consciente, ao menos no início, da sua truculência. Madalena tem aliados na sua luta: o Padilha, professor da escola que funciona dentro da fazenda e que tem idéias comunistas mais evidentes; o padre Silvestre, que tem princípios bastante próximos aos seus mas que se apresenta um tanto quanto ignorante sobre maiores detalhes da doutrina comunista; e D. Glória, sua tia, com a qual não tem exatamente uma proximidade política, mas tem proximidade ideológica e afetiva.

Paulo Honório também não está só: Azevedo Gondim e Nogueira têm uma visão de mundo parecida com a do narrador, mas mantêm em relação a ele uma diferença no mínimo fundamental, não são proprietários. De qualquer forma os aliados não minimizam o inferno em que vivem Paulo Honório e Madalena e os conflitos, ao contrário, só se agravam, principalmente porque o fazendeiro passa a ter ciúme de todos, inclusive dos seus amigos.

Quando Paulo Honório decide comprar São Bernardo de Padilha filho a fazenda estava em completa decadência: "Achei a propriedade em cacos: mato, lama e potó como os diabos. A casa-grande tinha paredes caídas, e os caminhos estavam quase intransitáveis. Mas que terra excelente!" (RAMOS, 1988, p. 16)

A decadência nesse momento está aliada também à decadência moral de Luís Padilha e ajuda Paulo Honório a barganhar no preço até o extremo. Ao se tornar proprietário de São Bernardo, Paulo Honório passa a se dedicar em tempo integral à modernização, inclusive tecnológica, da fazenda. Também seus limites são ampliados, cercas que haviam invadido a terra não só voltam aos seus lugares antigos como ainda vão adiante, Paulo Honório invade a terra dos vizinhos: 
"Depois da morte do Mendonça, derrubei a cerca, naturalmente, e levei-a para além do ponto em que estava no tempo de Salustiano Padilha." (RAMOS, 1988, p. 40). E: "E eu, o caminho aplainado, invadia a terra do Fidélis, paralítico de um braço, e a dos Gama, que pandegavam no Recife, estudando direito. Respeitei o engenho do dr. Magalhães, juiz." (RAMOS, 1988, p. 40)

São Bernardo cresce. Paulo Honório se torna cada vez mais poderoso, mas a fazenda só é vista no sentido prático, lugar onde tudo está lá para ser vendido, para se tornar capital. Mas a paisagem da fazenda ganha tintas poéticas num momento muito especial da narrativa, quando Paulo Honório e Madalena se casam:

Estávamos em fim de janeiro. Os paus-d'arco, floridos, salpicavam a mata de pontos amarelos; de manhã a serra cachimbava; o riacho, depois das últimas trovoadas, cantava grosso, bancando rio, e a cascata em que se despenham, antes de entrar no açude, enfeitava-se de espuma. (RAMOS, 1988, p. 94-95)

De fato esse é um momento de lirismo e de exceção. O tom normal de Paulo Honório é o da grandiloquiência, é o de ver São Bernardo como um grande feito pessoal e nos seus delírios chega a se imaginar afirmando:

- Vejam isto. Estão dormindo? Acordem. As casas, a igreja, a estrada, $o$ açude, as pastagens, tudo é novo. $O$ algodoal tem quase uma légua de comprimento e meia de largura. E a mata é uma riqueza! Cada pé de amarelo! Cada cedro! Olhem o descaroçador, a serraria. Pensam que isto nasceu assim sem mais nem menos? (RAMOS, 1988, p. 122)

Mas o tempo passa e esse quadro muda. Depois da Revolução de 30 e da morte de Madalena as coisas se tornam bem diferentes:

Entrei nesse ano com o pé esquerdo. Vários fregueses que sempre tinham procedido bem quebraram de repente. Houve fugas, suicídios, o Diário Oficial se emprenhou com falências e concordatas. Tive de aceitar liquidaçōes péssimas.

$O$ resultado foi desaparecerem a avicultura, a horticultura e a pomicultura. As laranjas amadureciam e apodreciam nos pés. 
Deixá-las. Antes isso que fazer colheita, escolha, embalagem, expedição, para dá-las de graça. (RAMOS, 1988, p. 178)

Os limites de São Bernardo também mudam:

Um dia em que, assim de braços cruzados, contemplava melancolicamente o descaroçador e a serraria, João Nogueira me trouxe a notícia de que o Fidélis e os Gama iam remexer as questões dos limites. E o pior era que o dr. Magalhães estava noutra comarca. (RAMOS, 1988, p. 179)

Gostaria de voltar a uma questão que já foi esboçada quando tratei da imagem em São Bernardo: o tempo da enunciação e o tempo do enunciado. Afirmei que esses dois tempos não coincidem no texto e que se pode mesmo falar num Paulo Honório narrador e em outro personagem. O narrador se integraria ao tempo da enunciação e a personagem ao tempo do enunciado. No entanto, a partir de determinado momento narrador e personagem se fundem e a narrativa se escoa no presente. Esse momento é marcado de várias maneiras, materialmente por ser o último capítulo do livro, mas também pela passagem dos dois anos da morte de Madalena, pela enorme solidão que escurece a vida de Paulo Honório e pela escritura de São Bernardo:

[...] diante de nós há dois fatos - o que é contado na obra e o que é da própria narração (deste último nós mesmos participamos como ouvintes-leitores); esses acontecimentos ocorrem em tempos diferentes (diferentes também pela duração) e em lugares diferentes; simultaneamente, eles estão indissoluvelmente unidos num acontecimento único, mas complexo, que nós podemos assinalar como a obra em sua plenitude factual, incluindo aqui seus dados materiais externos, seu texto, o mundo nele representado, o autor-criador e o ouvinte-leitor. Assim, nós percebemos essa plenitude na sua totalidade e indivisibilidade, mas ao mesmo tempo compreendemos também toda a diversidade dos elementos que a compõem. (BAKHTIN, 1988, p. 359)

O tempo da enunciação compreende cerca de quatro meses, quando Paulo Honório teria se sobressaltado pelo pio de uma coruja que o fazia lembrar 
Madalena no momento em que escrevia uma carta a um sujeito. É justamente essa relação com a escrita que desperta no fazendeiro o desejo de compor São Bernardo, o livro. O tempo do enunciado vai das primeiras reminiscências da infância do protagonista até o momento da escritura do livro e conseqüentemente do seu término. Mas o maior volume do tempo do enunciado é dedicado à conquista, posse e transformação de São Bernardo, a fazenda, até o seu declínio e o de seu proprietário. Não é possível saber pelo texto com quantos anos exatamente Paulo Honório estava quando adquire São Bernardo. Porém, ele afirma a Madalena ter quarenta e cinco anos pouco antes de se casarem. ${ }^{3}$ Depois sabemos que ficam exatamente três anos casados e que no tempo da enunciação faz dois anos que a moça morreu e que Paulo Honório está com cinqüenta anos, portanto se passaram cinco anos. E principalmente três deles, durante o casamento, merecem atenção especial, os últimos dois são somente evocados. Isto é, o narrador marca o tempo com precisão no que se refere a Madalena. Ele tinha quarenta e cinco anos quando se conheceram, sabe-se quando fizeram dois anos de casados e que Madalena se suicida no terceiro ano. Mas não é possível se estabelecer com precisão o tempo que transcorreu da compra de São Bernardo ao seu apogeu, justamente os anos em que esteve casado. Em termos, isso aponta para a enorme importância de Madalena na sua vida. $E$, na verdade, nem mesmo a idade de Paulo Honório é exata:

Para falar com franqueza, o número de anos assim positivo e a data de São Pedro são convencionais: adoto-os porque estão no livro de assentamentos de batizados da freguesia. Possuo a certidão, que menciona padrinhos, mas não menciona pai nem mãe. Provavelmente eles tinham motivo para não desejarem ser conhecidos. Não posso, portanto, festejar com exatidão o meu aniversário. Em todo o caso, se houver diferença, não deve ser grande: mês a mais ou mês a menos. Isto não vale nada: acontecimentos importantes estão nas mesmas condições. (RAMOS, 1988, p. 12)

Por não ter família Paulo Honório se torna assim o iniciador de uma nova, de maneira que ele é um empreendedor até mesmo nesse sentido. Casa-se com Madalena e tem um filho do qual não sabemos nem mesmo o nome, da criança só há uma imagem fragilizada:

3 A última referência à idade e ao próprio tempo é feita quando Paulo Honório tinha dezoito anos, é preso e fica três anos, nove meses e quinze dias trancafiado. 
E o pequeno continuava a arrastar-se, caindo, chorando, feio como os pecados. As perninhas e os bracinhos eram finos que faziam dó. Gritava dia e noite, gritava como um condenado, e a ama vivia meio doida de sono. Às vezes ficava roxo de berrar, e receei que estivesse morrendo quando padre Silvestre lhe molhou a cabeça na pia. Com a dentição encheu-se de tumores, cobriram-no de esparadrapos: direitinho uma rês casteada. Ninguém se interessava por ele. D. Glória lia. Madalena andava pelos cantos, com as pálpebras vermelhas e suspirando. (RAMOS, 1988, p. 136)

A presença do filho marca a passagem do tempo: antes dele nascer $\mathrm{e}$ depois que nasceu. Os momentos em que ele aparece é quase sempre chorando, fazendo barulho e recebendo indiferença tanto de Madalena quanto de Paulo Honório. A essa sonoridade corresponde a dos relógios de São Bernardo, um na casa e outro na igreja, mas este pára na noite em que Madalena comete suicídio:

Quando dei acordo de mim, a vela estava apagada e o luar, que eu não tinha visto nascer, entrava pela janela. A porta continuava a ranger, o nordeste atirava para dentro da sacristia folhas secas, que farfalhavam no chão de ladrilhos brancos e pretos. O relógio tinha parado, mas julgo que dormi horas. Galos cantaram, a lua deitou-se, o vento se cansou de gritar à toa e a luz da madrugada veio brincar com as imagens do oratório. (RAMOS, 1988, p. 164)

O filho também silencia com o passar do tempo: "Se ao menos a criança chorasse..." (RAMOS, 1988, p. 188). Paulo Honório se torna assim um homem que só possui seu passado, mesmo o filho, virtual representante do futuro, o herdeiro, se cala. Madalena, ao se matar, estabelece um silêncio definitivo entre ela e o marido. Os amigos desaparecem deixando Paulo Honório ainda mais só. E até mesmo o passado de Paulo Honório se finda com o término da escritura de São Bernardo, nem essa escritura tem mais futuro: "Levanto-me, procuro uma vela, que a luz vai apagar-se. Não tenho sono. Deitar-me, rolar no colchão até a madrugada, é uma tortura. Prefiro ficar sentado, concluindo isto. Amanhã não terei com que me entreter." (RAMOS, 1988, p. 184)

O fim de São Bernardo livro associado ao fim de São Bernardo fazenda representam juntos a total ausência de futuro de Paulo Honório. 


\section{Conclusão}

Em todas as situações cronotópicas elencadas é marcante a presença que o espaço e o tempo ocupam em São Bernardo.

Ao tratar da imagem de Paulo Honório verifiquei a alteração radical de ponto de vista que se processa no narrador, que vai do vencedor ao deformado e de quanto a passagem do tempo atua neste ponto de vista. No cronotopo do encontro privilegiei a sequiência distância-aproximação-distância que ocorre entre o protagonista e Madalena e especialmente a questão espacial que subjaz nesses encontros e desencontros. $O$ cronotopo da estrada foi facilmente aproximado à ascensão e queda da fazenda bem como com o caminho trilhado por Paulo Honório na escritura de São Bernardo. Na discussão da fazenda como espaço privado o parâmetro por excelência para ocupar o espaço público foi o mundo no seu sentido mais abrangente. Nesse momento aproveitei para demonstrar como que, ainda que privado, São Bernardo consegue reunir diferentes ideologias durante algum tempo. Igualmente trouxe à luz as influências que o contexto histórico tem sobre a fazenda e sua derrocada. Pelo fato de São Bernardo ser palco de praticamente toda a ação do livro, privilegiei seu espaço no sentido de demonstrar as mutações pelas quais passou.

A opção de deixar a discussão do tempo da enunciação e do tempo do enunciado para o final não foi casual. Creio que foi fundamental ter todos os elementos anteriores esclarecidos para poder entrar na questão do tempo. Nessa medida, é extremamente relevante a maestria e o cuidado com que Graciliano Ramos distribui milimetricamente - para ser espacial - o tempo ao longo do romance. Para acrescentar algo aos comentários tecidos no corpo deste trabalho, é marcante o fato de que no tempo da enunciação inicialmente surja um Paulo Honório mais viril e dinâmico e ao final ele esteja fragilizado e com os braços cruzados, imóvel. Essas imagens do narrador construídas no tempo da enunciação se coadunam perfeitamente com as imagens dele no tempo do enunciado, quando também se tem inicialmente um Paulo Honório viril e dinâmico e ao final ele se transforma naquele mesmo ser amargurado do tempo da enunciação, marcando a fusão dos dois tempos e seu conseqüente presente no último capítulo. 


\section{RESUMO}

Este texto apresenta uma reflexão sobre o tempo e o espaço no livro São Bernardo, de Graciliano Ramos. As idéias que utilizei são do pensador Mikhail Bakhtin.

Palavras-chave: Graciliano Ramos, cronotopo, Mikhail Bakhtin.

\section{RÉSUMÉ}

Ce texte présente une réflexion sur le temps et l'espace dans le livre São Bernardo, du Graciliano Ramos. Les idées que j'avais utilizée ici sont de le penseur Mikhail Bakhtin.

Mots-clé: Graciliano Ramos, chronotope, Mikhail Bakhtin.

\section{REFERÊNCIAS BIBLIOGRÁFICAS}

BAKHTIN, Mikhail. Formas de tempo e de cronotopo no romance. In: Questões de literatura e de estética. Trad. de Aurora Fornoni Bernardini et al. São Paulo: Hucitec, 1988.

RAMOS, Graciliano. São Bernardo. Rio de Janeiro: Record, 1988. 